\title{
The Monoclonal Antibody B30 Recognizes a Specific Neuronal Cell Surface Antigen in the Developing Mesencephalic Trigeminal Nucleus of the Mouse
}

\author{
Didier Y. Stainier ${ }^{2}$ and Walter Gilbert ${ }^{1}$ \\ Department of Cellular and Developmental Biology and ${ }^{2}$ Department of Biochemistry and Molecular Biology, Harvard \\ University, Cambridge, Massachusetts 02138
}

\begin{abstract}
A monoclonal antibody, B30, obtained with whole cells from embryonic brain as an immunogen, recognizes a neuronal cell surface antigen that appears only in 2 distinct systems in the developing mouse brain: the trigeminal system and the cerebellum. In the trigeminal system, B30 labels the surface of neurons, including their axons and their transient dendrites, in 2 groups of cells: the centrally located mesencephalic trigeminal nucleus and the peripheral trigeminal ganglion. Immunoreactivity is detectable during axon outgrowth, peaks around the seventh postnatal day, and disappears around 2 weeks after birth. In the cerebellum, B30 labels 2 layers of cells during development. Perinatally, and for about a week after birth, the layer of premigratory granule cells stains. After their maturation, Purkinje cells start to stain and by $12 \mathrm{~d}$ postnatally all the Purkinje cell bodies, their axons, and their dendritic trees show strong immunoreactivity. Subsequently, and in the adult, this staining is lost from some cells to reveal bands of antigen positive and negative Purkinje cells. Initial biochemical characterization of the epitope shows that it is carried on 2 minor gangliosides.
\end{abstract}

Cell surface molecules have been postulated to be involved in axonal growth and guidance, target recognition, and synapse formation (Weiss, 1947; Sperry, 1963; Roseman, 1974; Hood et al., 1977). The identification of such molecules specific for subsets of neurons would not only provide us with a way to isolate these cells but also with a biochemical tool to test for specific recognition processes. Since the monoclonal antibody technique was introduced into neuroscience (Barnstable, 1980; Zipser and McKay, 1981), several groups have successfully raised monoclonal antibodies to regionally restricted cell surface antigens in both invertebrate (Goodman et al., 1984; McKay et al., 1984) and vertebrate species (Cohen and Selvendran, 1981; McKay and Hockfield, 1982; Fujita and Obata, 1984; Stallcup et al., 1985; Constantine-Paton et al., 1986; Moskal and Schaffner, 1986; Yamamoto et al., 1986; Mori et al., 19.87). Those

Received Sept. 17, 1988; revised Nov. 28, 1988; accepted Dec. 2, 1988

We thank Dr. Helen Rayburn and Dr. Hen-Ming Wu, who took part in the early stages of this project. We also thank Beth Bennett for expert technical help and advice in tissue culture, Albert Ko for advice on TLC techniques, Dr, K. Lloyd for mAb R24, Lloyd Schoen bach for help with figures, and Dr. Carl Fulwiler for critical reading of the manuscript.

Correspondence should be addressed to Dr. Walter Gilbert, Department of Cellular and Developmental Biology, Harvard University, 16 Divinity Ave., Cam. bridge, MA 02138 .

Copyright (C) 1989 Society for Neuroscience $0270-6474 / 89 / 072468-18 \$ 02.00 / 0$ studies reveal a number of general and some more specific molecules associated with the extracellular matrix and the cell membrane and point to a combinational and hierarchical system determining growth cone guidance and target recognition (see Bastiani et al., 1987; Steller et al., 1987; and for a review, see Jessel, 1988).

We have generated monoclonal antibodies to single-cell suspensions from embryonic mouse and rat brains and isolated hybridomas that define subpopulations of neurons by cell surface immunoreactivity. Parts of this effort have been reported previously (Rayburn et al., 1987; Stainier et al., 1987). This paper describes a monoclonal antibody, $\mathrm{mAb} B 30$, which identifies small populations of cells in the devcloping mouse CNS. $\mathrm{B} 30$ defines neurons and their processes in the mesencephalic trigeminal nucleus (MesV) and also outlines neurons in the trigeminal ganglion. Furthermore, it labels specific layers in the cerebellum at various times in development.

\section{Materials and Methods}

Monoclonal antibody production and screening. Timed pregnant female rats and mice were obtained from Charles River and housed until the appropriate gestational age (embryonic day 15 or E15). Animals were killed either by cervical dislocation or euthanized with ether. Uteri were dissected from pregnant animals into ice-cold PBS (pH 7.4), individual embryos were removed, and the mid- and hindbrains were dissected free of other tissue and stripped of their membranes. Using fire-polished pasteur pipettes of decreasing bore size, a cell suspension was prepared and washed several times in PBS. This was then used as an immunogen at $10^{6}$ cells per injection following the standard immunization schedule: one intraperitoneal (i.p.) injection every 3 weeks for 9 weeks and the spleen fused $4 \mathrm{~d}$ after the last injection. Dimethyl dioctadccyl ammonium bromide (DDA, Eastman Kodak Co.; Baechtel and Prager, 1982) was used as an adjuvant and administered i.p. $4 \mathrm{hr}$ before the injection of the cells. Spleen cells were fused by conventional techniques using FOX-NY as the myeloma cell line (Galfre et al., 1977). (E15 rat midand hindbrain cells provided the immunogen for the fusion that led to the isolation of the B30 hybridoma.) The resulting hybrid cell lines were screeened first on chunks of embryonic mouse brain and subsequently on $120-\mu \mathrm{m}$-thick vibratome sections of newborn mouse brain using the following staining conditions: after incubating for $1 \mathrm{hr}$ in $10 \%$ normal goat serum (NGS) diluted in PBS, the tissue was exposed to supernatant of hybridoma culture overnight at $4^{\circ} \mathrm{C}$, then, after washing several times with $10 \%$ NGS/PBS $(2 \times 5 \mathrm{~min})$, antibody binding was visualized by incubation with a fluoresceinated goat anti-mouse IgG + IgM (Boehringer-Mannheim) diluted 1:40 in PBS for $2 \mathrm{hr}$. After a final wash in PBS $(2 \times 10 \mathrm{~min})$, the tissue chunks were examined.

The initial screen consisted of staining chunks in 96-well plates (see Results). Controls for nonspecific fluorescence are included in each plate and reveal faint background fluorescence on some morphologically distinct cells which can be eliminated with incubation in increasing concentrations of NGS (the background binding is attributed to Fc receptors on microglial cells). Statistically, in the original fusion, $95 \%$ of the wells 
showed hybridoma colonies (1-5/well); $10 \%$ of the wells screened showed cell surface immunoreactivity on a portion of cells in the CNS and another $15 \%$ reacted with various fibrillary structures.

Lines producing antibodies of interest were clones by limiting dilution and antibody subclass was determined by the Ouchterlony immunodiffusion technique (Miles Scientific).

Immunohistochemistry. Fresh brains of fetal and postnatal mice were embedded in $2.5 \%$ LGT agarose in PBS. We used a vibroslice from W.P.I. (New Haven, CT) to cut $100-$ to $120-\mu$ m-thick vibratome sections. The slicing was usually done at room temperature, though we found it easier to cut thinner sections in precooled buffer. All the immunohistochemical reactions were performed at room temperature (with gentle shaking) on free-floating sections in polystyrene culture dishes by sequential incubations in 10\% NGS in PBS for $1 \mathrm{hr}$; B30 hybridoma culture supernatant nvernight (12-18 hr); after several washes with $10 \%$ NGS/PBS $(2 \times 10 \mathrm{~min})$ fluoresceinated goat anti-mouse IgM (Southern Biotech), diluted 1:100 for $2 \mathrm{hr}$. After several more washes in 10\% NGS/ PBS $(2 \times 10 \mathrm{~min})$, the sections were slightly fixed if longer preservation was needed ( $1 \%$ paraformaldehyde for $30 \mathrm{~min}$ either before or after incubation with the secondary antibody) and mounted in fresh mounting medium (90\% glycerol in PBS containing $1 \mathrm{mg} / \mathrm{ml} p$-phenylenediamine and $0.1 \%$ sodium azide). They were examined in the culture dishes or between 2 coverslips separated by silicone grease. A Nikon DiaphotTMD inverted microscope equipped with epifluorescence was used as well as a Lasersharp MRC-500 confocal microscope. Appropriate controls were done, including other identified mouse IgMs and extended incubations with the secondary fluorosceinated antibody. The resulting background fluorescence was negligible (see Results).

Cell culture and staining. E1 3 mouse trigeminal ganglia were dissected and triturated, and the cells were plated on collagen coated plates in L-15 medium with $10 \%$ CBS or in HB101 medium (Hana Biologics). NGF $(50 \mathrm{ng} / \mathrm{ml})$ was added to the cultures. Live cultures were stained as described above (first $\mathrm{Ab}$ for $40 \mathrm{~min}$ and second $\mathrm{Ab}$ for $20 \mathrm{~min}$ at room temperature), 2 and $6 \mathrm{~d}$ after plating. Cultures were returned to the incubator after observation.

Ganglioside preparation and TLC analysis. Freshly dissected postnatal day 7 (10 P7 mice) brain stem ( + MesV containing areas of the midbrain), P7 occipital cortex ( 10 mice), and P12 ( 10 mice) cerebellum were homogenized in chloroform/methanol $(2: 1, \mathrm{vol} / \mathrm{vol})$ and extracted with $0.12 \mathrm{M} \mathrm{KCl}$ (Suzuki, 1965). The extracts were dried by rotary evaporation, taken up in water, desalted through Bond-Elut columns (Analytichem International) and finally lyophilized for storage at $-20^{\circ} \mathrm{C}$.

Thin-layer chromatography of gangliosides was done on aluminiumbacked TLC plates (silica gel $60,0.2 \mathrm{~mm}$ thick, E. Merck). The plates were preactivated by heating them to $110^{\circ} \mathrm{C}$ for $30 \mathrm{~min}$ and developed in chloroform/methanol $/ 0.25 \%$ aqueous $\mathrm{CaCl}_{2}$ (60:40:10). Ganglioside standards were obtained from Calbiochem and were detected by resorcinol stain. R24 (anti-GD3) was a generous gift from Dr. K. Lioyd. After drying, the plates were dipped in $0.05 \%$ poly(isobutylmethacrylate) (Polysciences) in hexane for $90 \mathrm{sec}$. The dried chromatograms were sprayed with PBS before soaking in a blocking solution (PBS, 3\% BSA, and 5\% NGS) for $30 \mathrm{~min}$ (all the incubations were done at room temperature with gentle shaking). The chromatograms were overlaid with the first antibody (diluted hybridoma supernatant) for $3 \mathrm{hr}$. After repeated washes in PBS, the chromatograms were overlaid with alkaline phosphatase-conjugated second antibody (diluted 1:1000) for $1 \mathrm{hr}$. After repeated washes in PBS, BCIP, and NBT (BRL) were used at a 1:1 molar ratio in $0.1 \mathrm{M}$ Tris- $\mathrm{HCl}(\mathrm{pH} 9.5), 0.1 \mathrm{M} \mathrm{NaCl}, 50 \mathrm{mM} \mathrm{MgCl}$ for the color reaction. Upon completion, the reaction was stopped in water

Enzyme treatments and chromatography on DEAE-Sephadex A-25 (Pharmacia) were done as described by Schwarting et al. (1987).

\section{Results}

\section{Techniques}

We needed to develop quick and efficient methods to screen for monoclonal antibodies (mAbs) binding to cell surface antigens that would define rare subsets of neurons in the developing CNS. For the initial screenings, the embryonic brains were gently triturated with a polished pasteur pipette, and the resulting pieces were aliquoted into 96-well plates for immunochemical treatment with supernatant from the fusion plates. We then used an inverted microscope to examine individual wells. If greater resolution was needed, the sample could be taken out of the well and pressed gently between 2 coverslips for further observation. Various staining patterns appeared in the 96-well plates: staining of most cells, staining of most cells in some chunks, staining of some cells in some chunks, staining of fibrillary structures. Some $20 \%$ of the wells screened were selected for further immunohistochemical characterizations.

In order to display the surface staining of unfixed cells, we stained thick sections $(120-150 \mu \mathrm{m})$ of fresh tissue. These sections enable us to screen easily a sizeable fraction of the developing CNS to localize rare antigens. Staining fresh tissue permits a clear visualization of the surface staining of cells and processes. In embryonic and perinatal tissue, the antibody penetrates through the sample, and one can follow axons through and across the section for long distances. In the adult, only the surface layers of the section stain. The vibratome slices were processed as floating sections in $35 \mathrm{~mm}$ culture dishes. This approach involving fresh sections was analyzed for various immunohistochemical artifacts. The cells' death in these vibratome sections occurs quite readily. Cells in the superficial layer are broken from the cutting action of the blade, and other cells will die over time from a lack of nutrients and the conditions of incubation. Controls that showed that the staining patterns are not due to some artifactual staining of dead or damaged cells included using other mouse mAbs as well as a variety of incubations in the secondary fluoresceinated antibody. Furthermore, a number of antibodies of the IgM isotype: B5, B14, $\mathrm{B} 25$, and $\mathrm{C} 6$ were characterized in parallel with B30 (also an IgM). B5 and B25 stain neuronal cells on their surface, while B14 and C6 stain intracellular antigens of fibrous appearance. None of the above antibodies shared any of the specific staining properties of B30 either in the trigeminal system or in the cerebellum (data not shown). Overnight incubation in a commercial mixture of mouse IgMs followed by overnight incubation in fluoresceinated goat anti-mouse IgMs antibodies typically resulted in a low overall background. Thus, the patterns we describe depend on staining with a specific first antibody. Furthermore, the thickness of the section makes it possible to observe cells staining at a depth away from the broken surface layer.

\section{The trigeminal system}

Primary sensory neurons of the trigeminal system divide themselves between the trigeminal ganglion and the MesV. The latter forms a narrow layer of scattered monopolar neurons at the lateral margins of the periaqueductal gray matter and extends from the level of the trigeminal motor nucleus caudally to the lcvel of the supcrior colliculus rostrally. McsV neurons are the cell bodies of primary afferents and are the only such cells to be found within the adult vertebrate CNS. They are also the largest sensory neurons in the CNS. In the adult mouse brain, they number about 1500 (Hinrichsen and Larramendi, 1969). Although many more are generated during embryonic development, there is a period of extensive cell death around birth (Alley, 1974; Hiscock and Straznicky, 1986).

\section{The trigeminal ganglion}

B30 labels neurons of the trigeminal ganglion (TG) and their processes (Fig. 1A). This micrograph shows a parasagittal section of an E13 mouse head stained with B30. The central branches of the afferent neurons in the TG enter the pontine region of the brain stem (b), turn towards the spinal cord, and ramify in their various termination areas in the brain stem and the spinal 

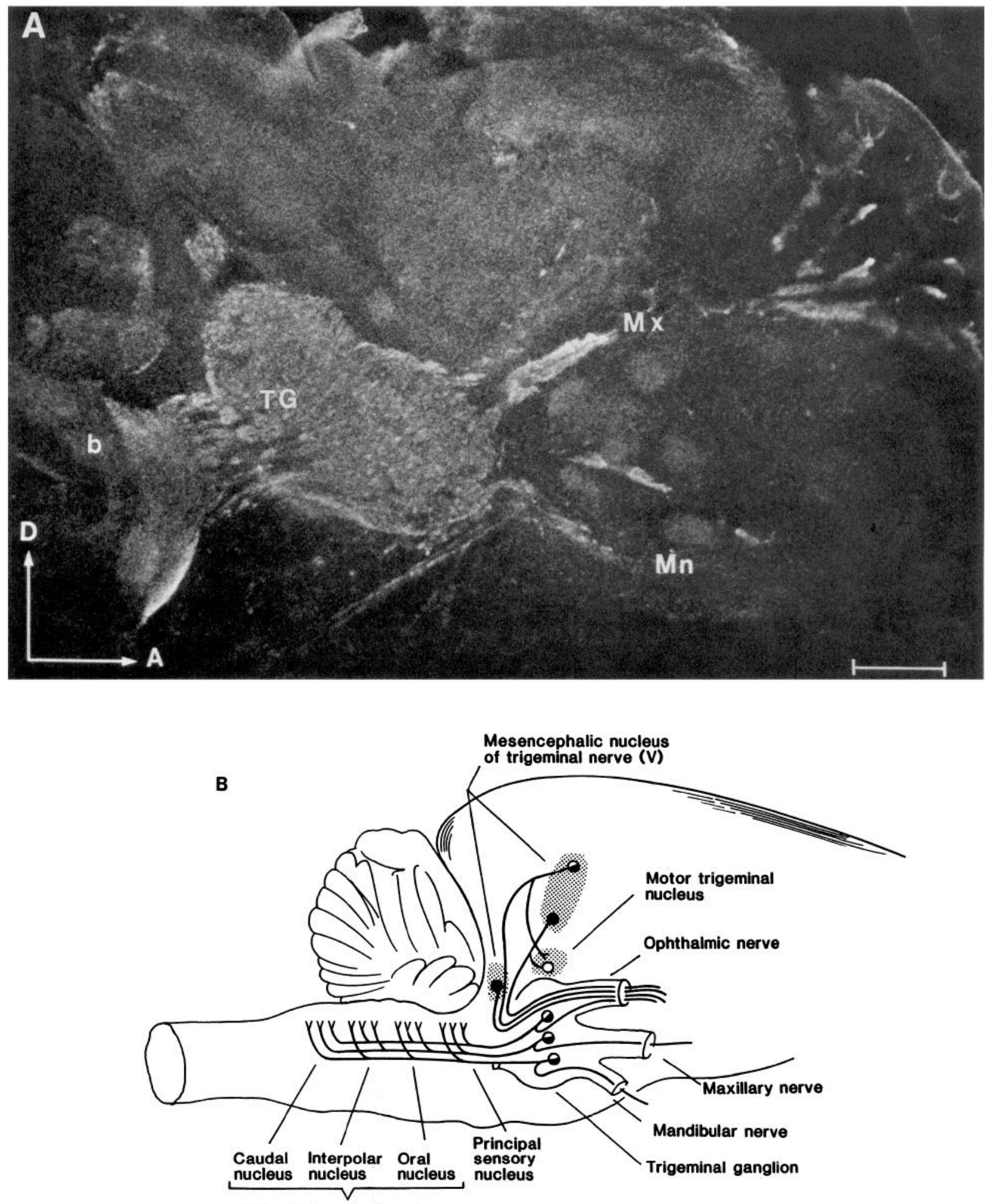

Spinal trigeminal nucleus

Figure 1. A, B30 labels neurons of the TG. Parasagittal section of embryonic day 13 (E13) mouse head stained with B30. Immunoreactivity outlines the ganglion, its connection to the brain stem $(b)$ dorsally as well as parts of its maxillary $(M x)$ and mandibular $(M n)$ peripheral projections. $D$, dorsal; $A$, anterior. Scale bar, $300 \mu \mathrm{m}$. $B$, Central connections of the trigeminal nerve. Schematic representation in the sagittal plane. The sensory nuclei of the trigeminal nerve receive afferent input from the skin of the face and oral mucosa, from the ciliary muscle of the eye as well as from receptors in the facial musculature and the temporomandibular joint. The central branches of the afferent neurons in the TG enter the pontine region of the brain stem. They terminate in the principal sensory nucleus and the nuclei of the spinal trigeminal tract-the oral, the interpolar, and the caudal. Collaterals of MesV neurons go to the motor nucleus of the trigeminal nerve. B30 immunoreactivity defines neurons in both the TG and $\mathrm{MesV}$ as well as their axons (central and peripheral projections). 


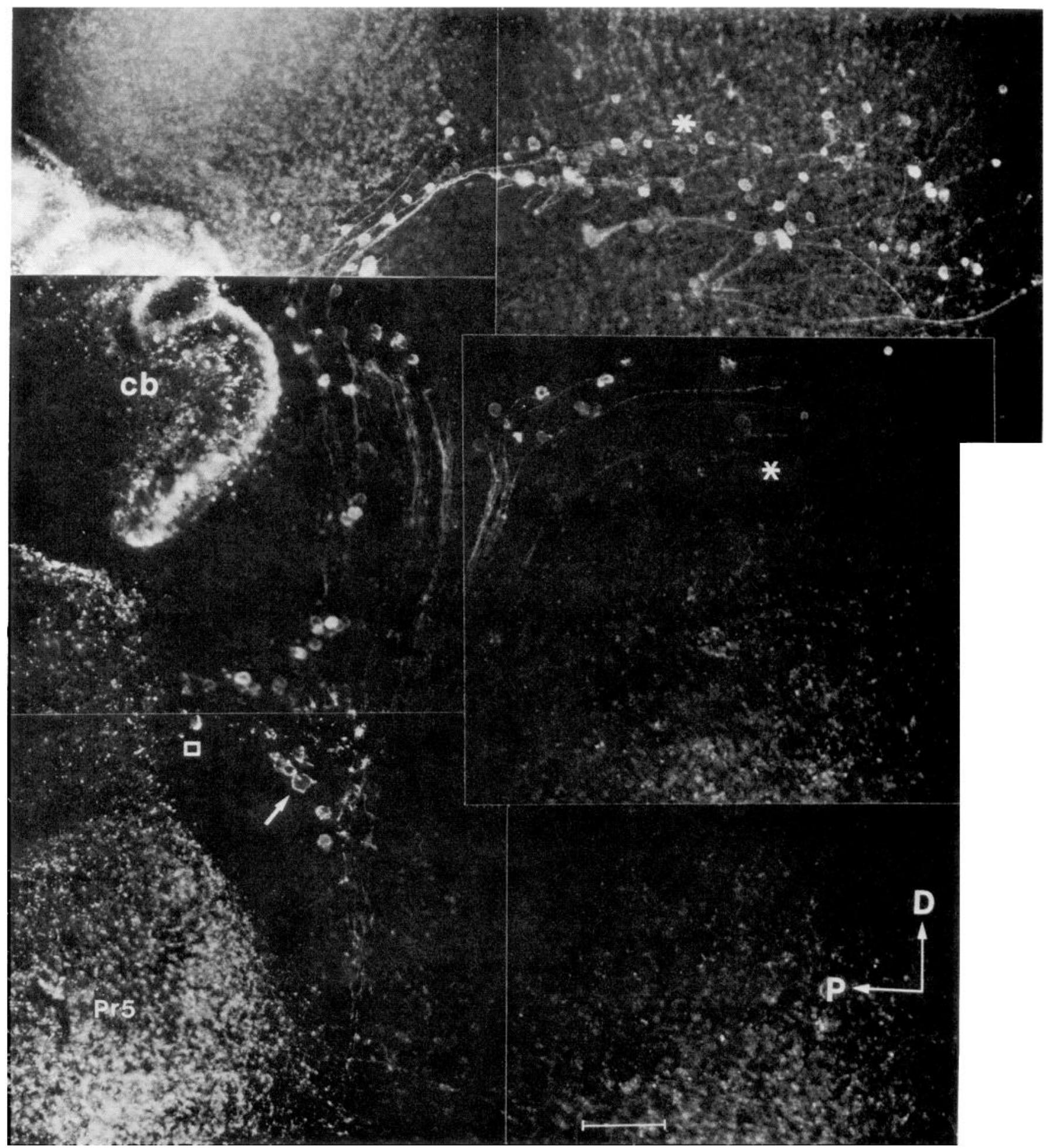

Figure 2. B30 labels neurons of the mesencephalic trigeminal nucleus. Parasagittal section of P4 mouse brain stained with B30. Immunoreactive axons can be followed for several millimeters. The nucleus can be divided into superior (stars) and inferior (arrow) parts; the cells of the superior part, at the level of the superior colliculus rostrally, send axons brushing past cells of the inferior part at the level of the trigeminal motor nucleus caudally. Some cells of the caudal group extend up into the cerebellar peduncles (square). Caudally immunoreactive areas apparent here include premigratory granule cells in the cerebellum $(c b)$, spinocerebellar fibers, and the innervated principal sensory nucleus $(\operatorname{Pr} 5)$. $D$, dorsal; $P$, posterior. Scale bar, $200 \mu \mathrm{m}$. Smaller cells of the dorsal group are about $20 \mu \mathrm{m}$; the larger cells of the ventral group, $35 \mu \mathrm{m}$. 


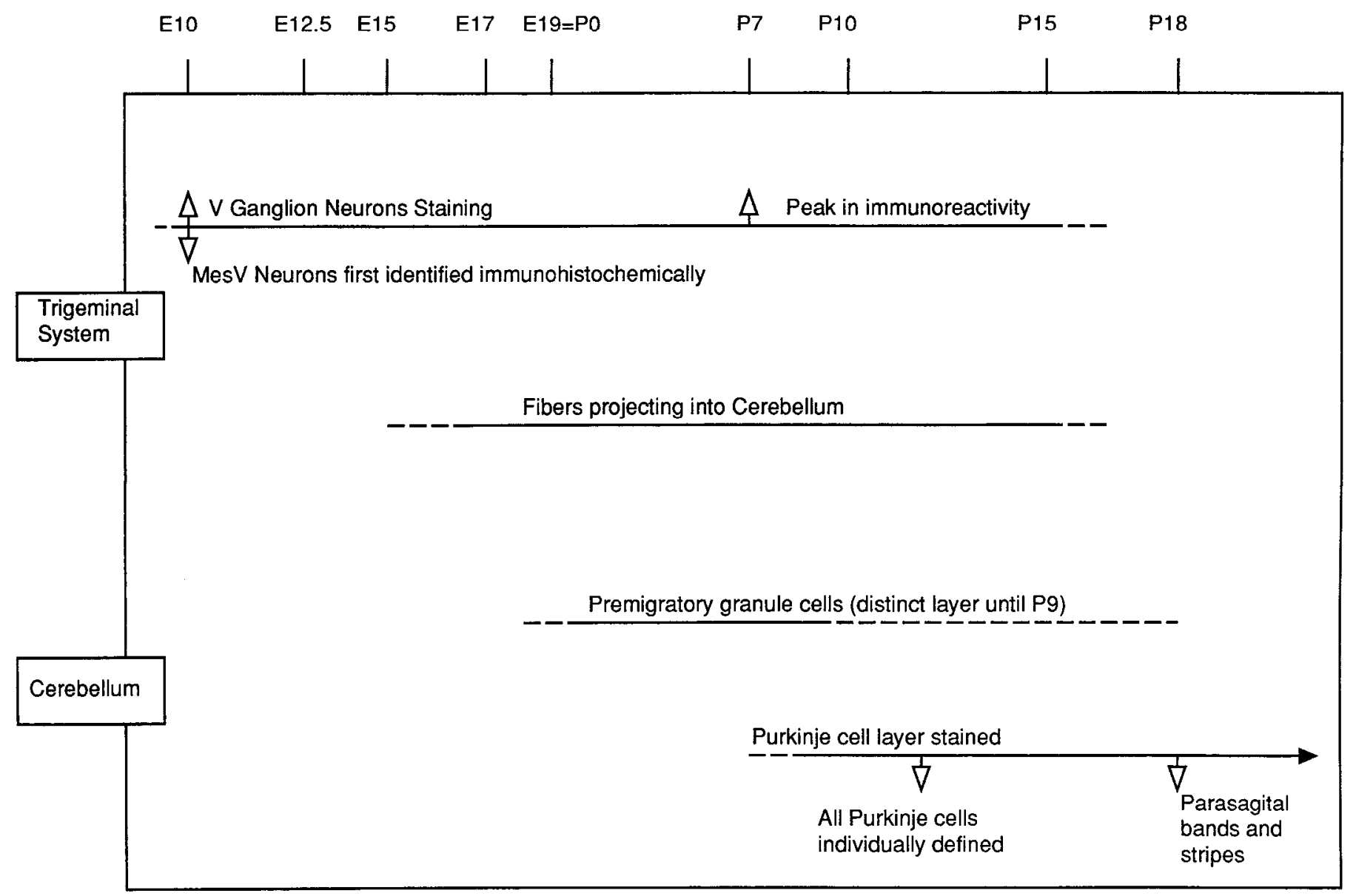

Figure 3. Chart of time course of B30 expression in the developing mouse CNS: it is limited to the trigeminal system (including the TG in the PNS) and the cerebellum. Horizontal dotted lines at ends of bars reflect uncertainty as to exact time point of onset or termination of B30 expression between sample days.

cord Peripherally, the trigeminal nerve branches out into 3 major nerves: the ophthalmic (not shown), the maxillary (Mx), and the mandibular (Mn). The specific B30 immunoreactivity allows us to look at the central regions that the TG innervates, thereby confirming results obtained by anatomical and electrophysiological methods. The main termination areas in the CNS are located in the principal sensory nucleus and the 3 nuclei of the spinal trigeminal tract - the oral, the interpolar and the caudal (see Fig. $1 B$ for a schematized representation of the trigeminal system and its major connections).

\section{The mesencephalic trigeminal nucleus}

The montage in Figure 2 shows a parasagittal section of a P4 mouse brain stained with B30; neurons in the MesV as well as their axons and collaterals are stained, and the immunoreactive axons can be followed for several millimeters. The MesV nucleus is flat and generally lies in only 1 or 2 of the thick parasagittal scctions. The nucleus exhibits 2 main groups of neurons in the superior part (stars) and one group in the inferior part (arrow). Also, axons from dorsorostrally located cells brush past cells in the ventrocaudal region. In this latter region, MesV neurons can be seen advancing right into the cerebellar peduncles (square). At this time, B30-immunoreactive premigratory granule cells also delineate the cerebellar folds (cb). Temporally, we have identified B30-positive MesV neurons in embryos as early as E10 (embryos stained as whole amounts; data not shown).
B30 immunoreactivity in the MesV peaks around P7 and fades out after 2 wecks postnatally. In the ccrcbcllum, premigratory granule cells stain as a distinct layer from E18 to P9. As we shall show later, Purkinje cells become immunoreactive starting at $\mathrm{P} 7$ and continue up to the adult stage. Figure 3 outlines the spatiotemporal distribution of B30 immunoreactivity.

Because of their central location and their supposed origin from the neural crest (Narayanan and Narayanan, 1978), MesV neurons have been an interesting and convenient group of neurons for anatomical, histological, and physiological investigations from the time of Meynert (1872). These cells establish their peripheral connections postnatally in line with the relatively late establishment of tooth development and innervation and the late appearance of secondary endings in the muscle spindles of the jaw. Synaptogenesis within the mesencephalic nucleus takes place at the same early postnatal period (Alley, 1973). At this time of hypothesized synapse formation within the nucleus, the neurons are very sharply outlined by B30 immunoreactivity. Staining of horizontal sections shows the semilunar arrangement of the nucleus, thereby confirming its identity. Figure 4 shows 2 crescent-shaped nuclei laterally surrounding the aqueduct $(\mathrm{Aq})$, while most MesV axons run together rostrocaudally. In this figure, immunoreactive premigratory granule cells delineate the rostral part of the cerebellum $(\mathrm{Cb})$. Within the nucleus, B30 immunoreactivity does not define geographical subpopulations of neurons, although there is a certain quanti- 


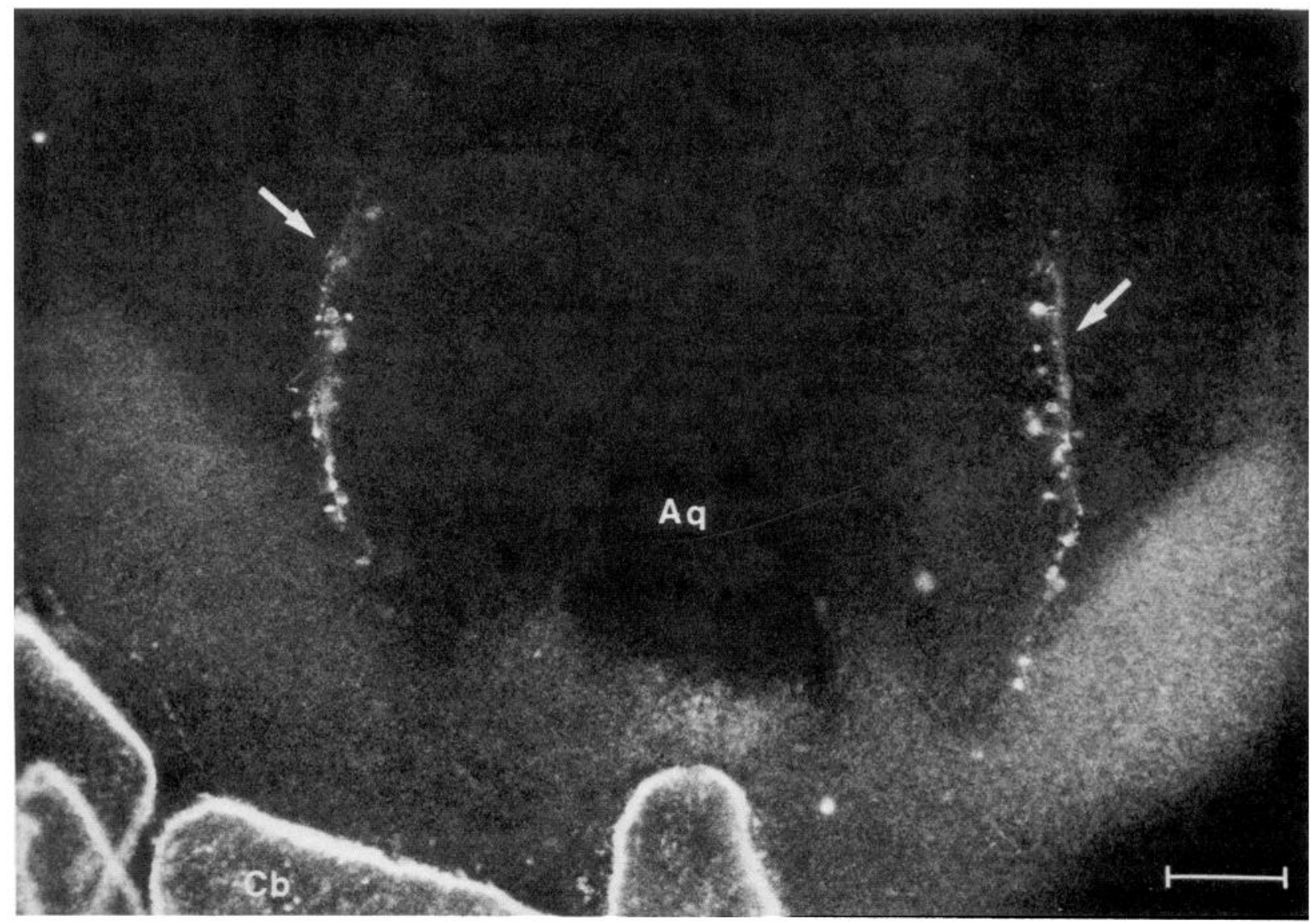

Figure 4. Semilunar arrangement of the trigeminal mesencephalic nucleus (arrows). Horizontal sections of P5 mouse brain stained with B30. Micrograph showing the arrangement of the MesV nucleus around the Aqueduct of Sylvius $(A q)$. The immunoreactivity observed caudally is associated with the cerebellum $(C b)$. Scale bar, $300 \mu \mathrm{m}$.

tative range of staining intensity. We estimate that $10-15 \%$ of the MesV neurons do not stain at P7, but this heterogeneity may be due to the presence of naturally dying or dead neurons.

We have followed MesV axons and collaterals that terminate in brain-stem regions such as the trigeminal motor nucleus and the reticular areas. Cerebellar projections of MesV have also been suggested from axonal transport studies (Saigal et al., 1980; Somana et al., 1980). Figure 5 shows B30-positive fibers (arrow), thought to originate from the spinal cord, projecting specifically to the 2 caudalmost cerebellar lobules. The inset is a low-power micrograph of the same field: the staining of premigratory granule cells delineates the entire cerebellum, while the B30-reactive fibers terminate specifically in the caudalmost area. We also have observed stained $\mathrm{MesV}$ neurons advancing right into the cerebellar peduncles. The B30-immunoreactive neuron that sits at the center of Figure 6 sends an axon towards the cerebellum (Cb). This axon was traced into the caudalmost cerebellar lobule (out of the field of this picture). So although we have not yet determined the origin of the B30-immunoreactive spinocerebellar projections, this immunohistochemical technique allowed us to confirm the hypothesized cerebellar projections of a few MesV neurons.

Perinatally, an area around the amygdala contains a few unresolved immunoreactive neurons and axons (data not shown).

\section{Morphology of the MesV neurons}

Our immunohistochemical data reveal interesting steps in the morphogenesis and organization of $\mathrm{MesV}$ neurons, confirming light microscopic studies done by Hinrichsen and Larramendi (1969), Alley (1974), and others.

Within the MesV nucleus, cell size variation is apparent; large cells (30-35 $\mu \mathrm{m})$, pear-shaped and usually unipolar, occupy in general the ventral portion of the nucleus (Fig. $7 A$, arrow). Medium-sized (Fig. 7A, star) and small cells, more irregular in shape, are mostly unipolar though some are bipolar; they predominate in the rostral and ventromedial part of the nucleus. Perinatally, axons of dorsal cells can be seen to form en passant transient axodendritic contacts with more medial cells exhibiting a few dendrites (Fig. $7 B$, arrows). Ventrocaudally those same axons come by the cells of the inferior part of the nucleus at such close proximity that the soma and bypassing axons cannot be separated optically. These latter cells exhibit boutonlike structures, thus suggesting axosomatic connections (see Hinrichsen and Larramendi, 1968). Postnatally, the cell surface is also studded with small spines, which may be vestiges of resorbed dendrites or might reflect increases in its surface area to help the cell in its metabolism (Hinrichsen and Larramendi, 1969) (Fig. 7C). Alternatively, the close timing of spine formation and synaptogenesis in the MesV (starting around postnatal day 5 for a period of $10 \mathrm{~d}$ in the hamster; see Alley, 1973) suggests that these surface structures may participate in synapse formation. Neurons are sometimes seen closely juxtaposed (see Figs. 2, 7A). Extensive somasomatic contacts within these groups give rise to numerous plasmalemmal membrane specializations resembling gap junctions and suggesting electrotonic coupling (Hinrichsen, 1970; Baker and Llinás, 1971). 


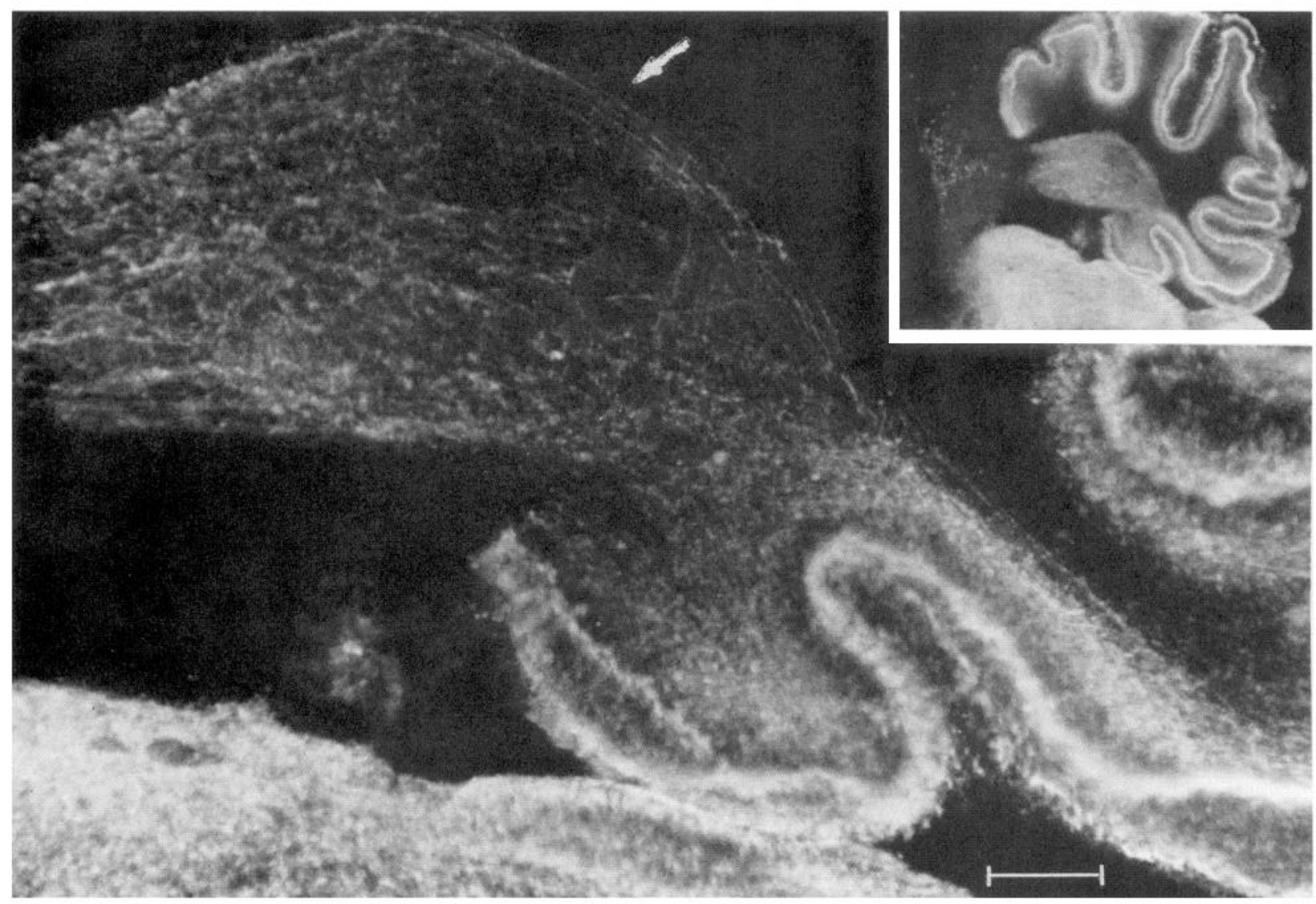

Figure 5. Immunoreactive fibers projecting into the cerebellum terminate specifically in the 2 caudalmost lobules. Parasagittal section of a P4 mouse cerebellum stained with B30. The cellular identity of their targets can not be determined at this stage as these axons do not establish synaptic connections until after 1 week postnatally. A confocal microscope is now being used to resolve the projection of these fibers on sections of older animals. Scale bar, $120 \mu \mathrm{m}$. Inset, Low power micrograph of the same field; MesV neurons can be observed advancing into the cerebellar peduncles while the B30 immunoreactive spinocerebellar fibers project specifically into the caudalmost lobules. The immunoreactivity in the region of the brain stem underlying the cerebellum outlines the termination areas of the central trigeminal projections in the spinal trigeminal nuclei.

\section{Cerebellum}

The B30-immunoreactive fibers reach well into the cerebellum by E15, hereby confirming findings by Mason (1985) and others. They observed that axons are present within cerebellar anlage for days before birth waiting for the differentiation of target cell dendrites. These axons establish synaptic connections during the second postnatal week.

The cerebellar folds are outlined by a thin layer of B30-reactive cells at E19. Figure 8 shows that at P5 only a specific subset of the external granule cell layer (EGL) is stained, i.e., the premigratory granule cells. They are seen just entering the molecular layer (ML). At postnatal day 7 (P7), B30 stains the premigratory granule cells as well as a layer just inside the ML: the monolayer where the Purkinje cells (PCs) are localized. Subsequently, individual PCs will become distinct. So at P12, as shown in Figure 9, $A, B$, all PCs, their axons and their dendritic trees are labeled. Purkinje axons (Fig. $9 A$, arrow) go through the internal granule cell layer (IGL) to the white matter where they gather to project mainly to the deep cerebellar nuclei. The dense staining of the ML in Figure $9 B$ is due to the heavily branched dendritic trees of the PCs. The fibers projecting into the cerebellum are staining very lightly at this stage. By P18, granule cell migration is completed (Larramendi, 1969).
By P18, a mosaic or banded pattern of staining of PCs appears. At this time, B30 selectively stains only certain PCs, their axons and their dendritic trees to form a mosaic of immunoreactive bands, which persists into the adult stage. This pattern is best viewed in horizontal sections of a 3-week-old mouse cerebellum as shown in Figure $10, A, B$. The immunoreactive PCs are clustered together in groups of varying sizes (usually from 5 to 10 PCs). These groups are most clear in the vermis, and they form parasagittal bands running rostrocaudally throughout the cerebellar cortex. The bands of B30-positive cells alternate with similar bands of B30-negative cells.

Figure $10 \mathrm{C}$ shows a pattern of thin immunoreactive stripes that extend across the ML. This pattern is seen mostly in the hemispheres and sometimes on the borders of the parasagittal bands described above. Each stripe is associated with an individual B30-positive Purkinje cell and lies 45-60 $\mu$ m away from the next stripe. These narrow structures may be Purkinje trees in their last stage of maturation: the dendritic trees mature morphologically and become isoplanar, running in a plane perpendicular to the axis of the folia, thus giving this striped staining pattern. A similar phenomenon has been observed by Hawkes and Leclerc (1987) using an anti-microtubule associated protein antibody (anti-zebrin; see Discussion), and they referred to is as satellite bands. 

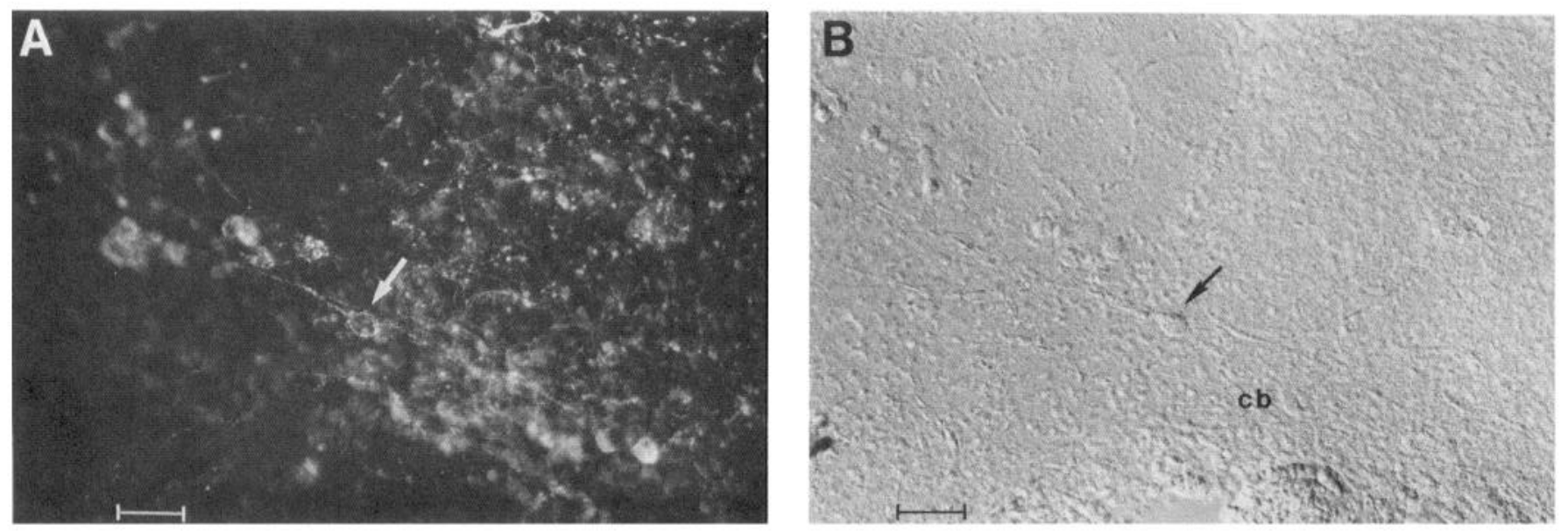

Figure 6. Projection of a MesV neuron into the cerebellum. A MesV neuron (arrow) advances into the cerebellar peduncles and sends an axon into the cerebellum $(c b) . A$, Fluorescent exposure of a parasagittal section (P5 mouse) stained with B30. $B$, Hoffman phase micrograph of the same field. Scale bars, $55 \mu \mathrm{m}$.

\section{Staining: antibody penetration in thick sections}

To address the problem of antibody penetration in thick sections, we examined a normally processed $120-\mu \mathrm{m}$-thick parallel section of a P5 brain with a Lasersharp MRC-500 confocal microscope and optically dissected it every $17 \mu \mathrm{m}$. Immunoreactive MesV neurons and axons appeared in every optical section. Figure $7 D$ shows a stereo pair, constructed by projecting the 8 sections with an offset of \pm 1 . This 3-dimensional view reveals a previously unobserved phenomenon in the MesV nucleus: a unipolar neuron sends an axon that apparently terminates on a passing axon (arrow).

\section{Cell surface staining}

We have been able to stain with B30 in vivo. Newborn mice were injected intracranially with B30 ascites $(10 \mu \mathrm{l}) ; 16 \mathrm{hr}$ later, they were either killed and processed normally (sections incubated for $2 \mathrm{hr}$ with fluoresceinated secondary antibody after a $6 \mathrm{hr}$ incubation in $10 \% \mathrm{NGS}$ ) or injected intracranially with 10 $\mu \mathrm{l}$ of undiluted fluoresceinated secondary antibody. These latter animals were processed $12 \mathrm{hr}$ after the second injection. Appropriate controls were done in parallel. In all cases, immunoreactivity defined a small area of trauma at the site of injection (around the fourth ventricle). However, B30 clearly defined a number of MesV neurons and their axons, fibers in the cerebellum reaching into the caudalmost lobules, and premigratory granule cells in the external granule cell layer. Figure $11 \mathrm{~A}$ shows a parallel section of a P3 mouse after sequential injection of both primary and secondary antibodies. A group of stained MesV neurons appears caudally (star), while more rostrally a well-defined MesV neuron sends an axon laterally (arrow). Also, the section shown in Figure 7, $A, B$ were both processed from brains injected with $\mathrm{B} 30$ ascites and stained, after sectioning, with the secondary antibody alone. These experiments directly confirm in vivo the cell surface immunoreactivity observed in the vibratome sections and also illustrate the relative permeability of the early postnatal brain.

Furthermore, live cultures of dissociated E13 mouse embryo TG were stained with $\mathrm{B} 30$. Figure $11 B$ shows the cell surface labeling of a B30-immunoreactive neuron $6 \mathrm{~d}$ after plating.

\section{B30 antigen}

Binding of $\mathrm{B} 30$ to cells in culture was eliminated by pretreating the cultures with organic solvents (chloroform/methanol, 2:1), suggesting that the antigen was a lipid. Mild proteolytic treatments of similar cultures did not affect their immunoreactivity (in fact, staining was slightly enhanced), and Western blots of membrane proteins prepared from B30-immunoreactive areas of P5 mouse brains did not reveal any specific antigen (data not shown). Figure 12 shows an immunostaining of a thin-layer chromatography (TLC) plate of acidic glycolipid extracts of dissected P7 midbrain and brain stem (B30 trigeminal immunoreactive areas), $\mathrm{P} 12$ cerebellum, and $\mathrm{P} 7$ cortex. Two discrete bands were found in both B30-immunoreactive areas but not in the cortex. One of the bands migrated slightly above GM1, the other migrated between GD1a and GD3 in a chloroform/ methanol/aqueous $\mathrm{CaCl}_{2}$ solvent system. No other immunoreactivity suggestive of lipoproteins or phospholipids was observed on the TLC plate. Neuraminidase digestion of P12 cerebellar acidic glycolipids and chromatography on DEAESephadex A25 showed that the antigens contain sialic acid (data not shown). These results imply that the B30 epitope is carried on by 2 distinct gangliosides. The migration pattern of the B30 antigen is similar to that of the Jones antigen (Schlosshauer et al., 1988), but they differ in the base lability of their epitopes (data not shown) and the relative distribution of immunoreactivity on TLC plate analysis of gangliosides from 2-week-old cerebellum (cf. Fig. 12, lane a, and Schlosshauer et al., 1988, fig. 4a, P14). Moreover, B30 immunocytochemistry in the developing rat CNS [where the Jones antigen was shown to be associated with neural cell and process migration (Mendez-Otero et al., 1988)] revealed no neuronal cell surface immunoreactivity except for that associated with the Purkinje cells (which parallels that observed in the mouse cerebellum).

\section{Discussion}

The monoclonal antibody $\mathrm{B} 30$ recognizes a cell surface antigen that is expressed selectively in the developing CNS of the mouse. Immunoreactivity is confined to 2 separate systems, the trigeminal system and the cerebellum. Spatiotemporally regulated, the 

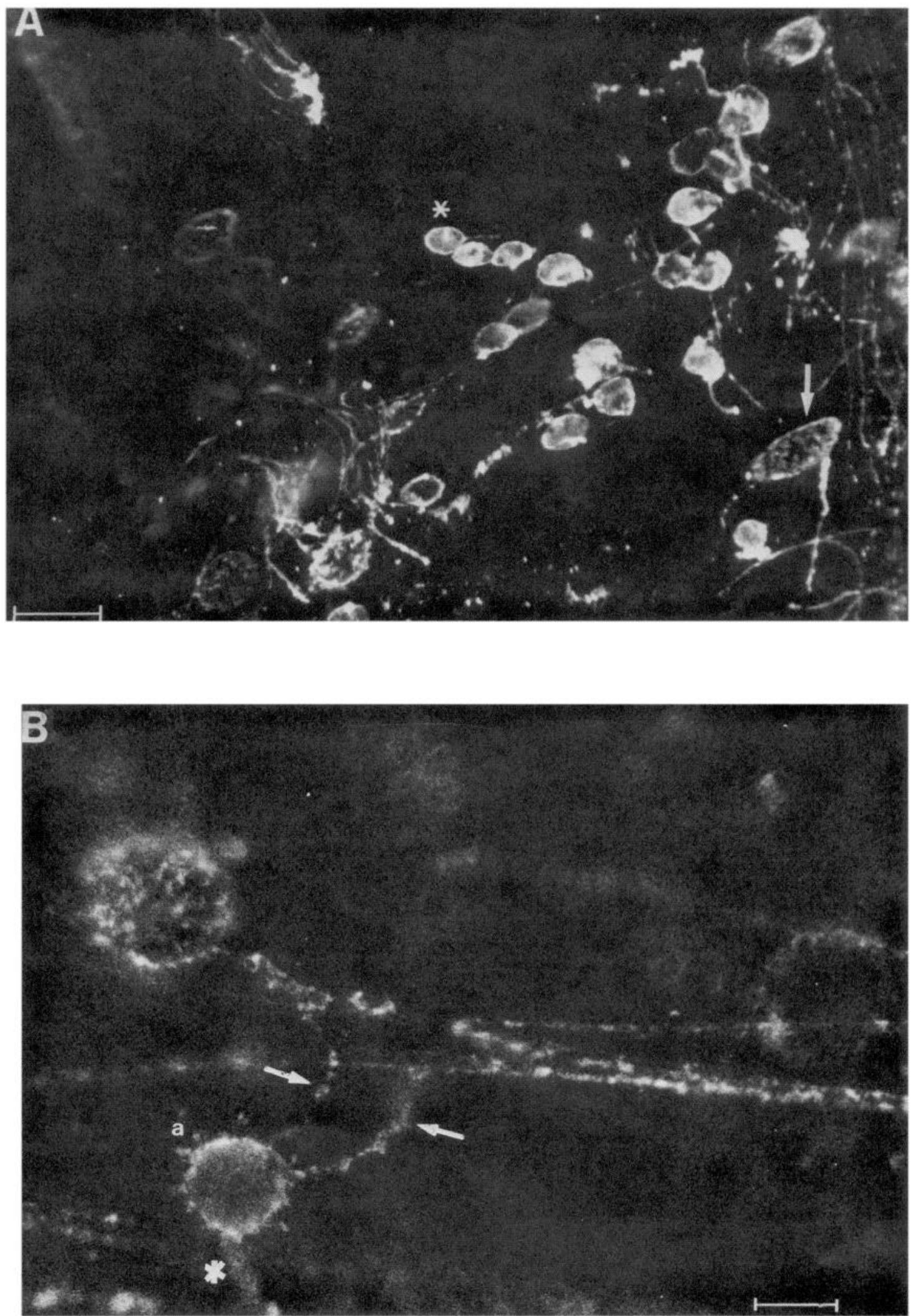

Figure 7. Morphological characteristics of MesV neurons. A, Cells, mostly unipolar, differ greatly in size. Large cells, 35-40 $\mu \mathrm{m}$ ( in the ventral part of the nucleus; smaller cells, $20-25 \mu \mathrm{m}($ star), predominate in the rostral part. Parasagittal section of a P7 mouse brain stained with B30; ventral region of the nucleus. Scale bar, $45 \mu \mathrm{m}$. B. Perinatally, short dendrites can be observed making axodendritic contacts. Parasagittal section of P3 mouse brain stained with B30. Neuron $(a)$ sends 2 short dendrites (arrow) which contact passing axons. Its axon (star) projects out of the plane of the picture. Scale bar, $25 \mu \mathrm{m}$. C, Cell surface is also studded with small spines whose role is unclear at this time. Fluorescent 

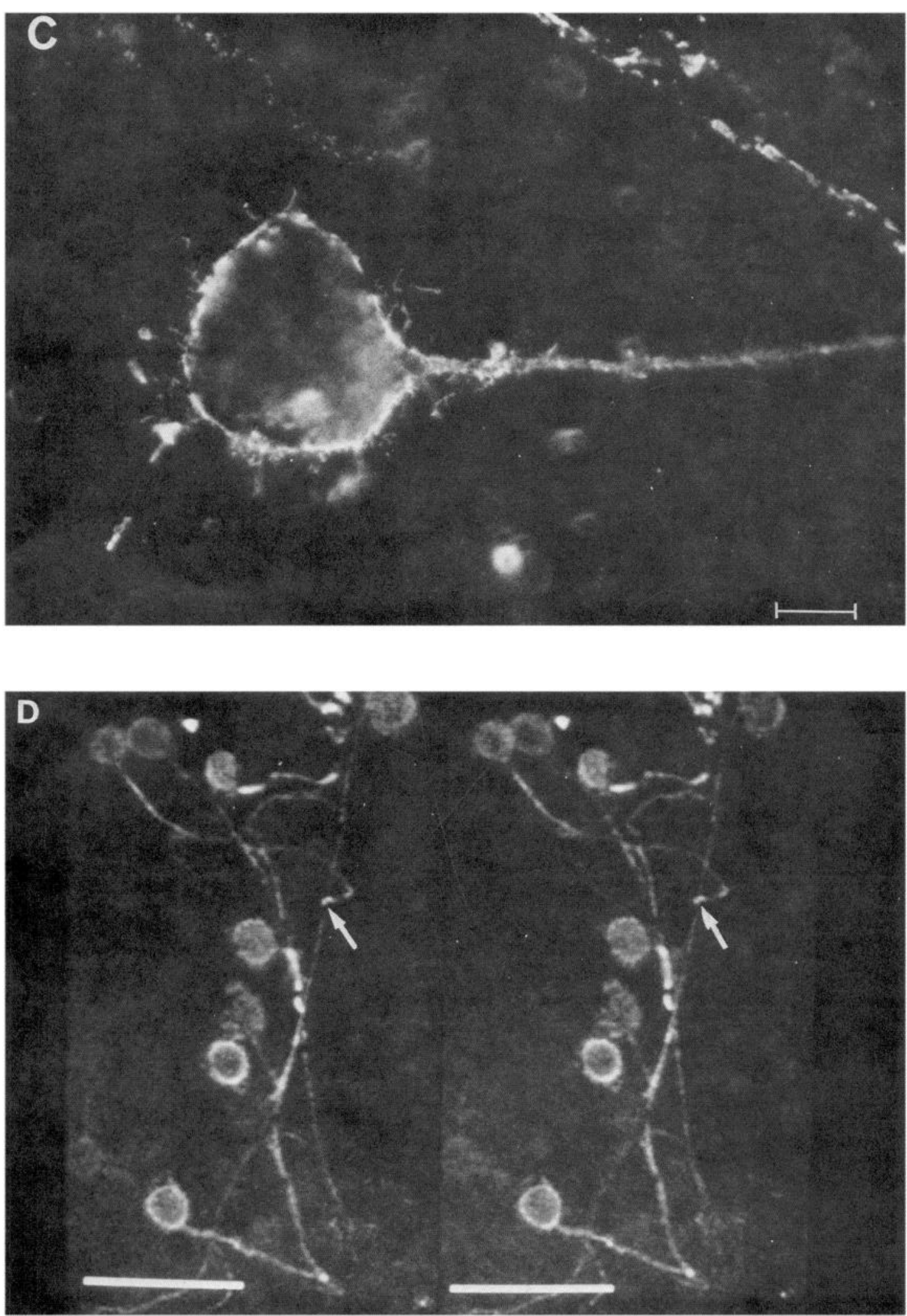

micrograph of a MesV neuron in a P7 mouse brain. Scale bar, $15 \mu \mathrm{m}$. D, Three-dimensional arrangement of MesV neurons. Horizontal section of a P6 mouse brain stained with B30 and observed with a Lasersharp MRC-500 confocal microscope. Stereo pair obtained by projecting 8 frames with opposing offsets. This method reveals several interesting features including an axoaxonal contact by which a specific axon apparently terminates on a passing vertical axon (arrow). Scale bar, $50 \mu \mathrm{m}$. 

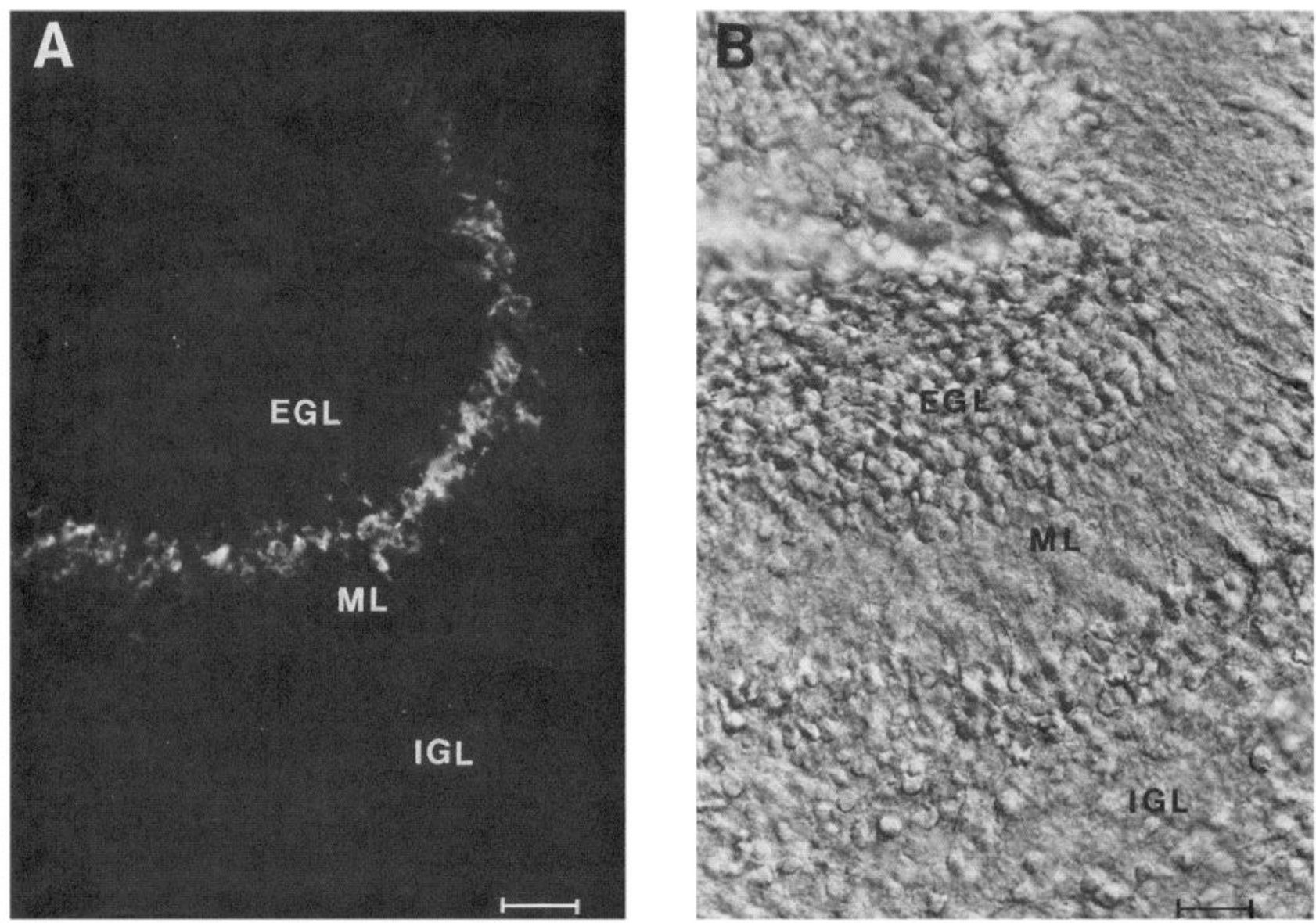

Figure 8. B30 labels the premigratory granule cell layer in early postnatal cerebellum. A, Parasagittal section of mouse P5 cerebellum stained with B30. At this stage, only a subset of the cells in the external granule cell layer $(E G L)$ are staining. They form the layer of postmitotic cells just outside the molecular layer $(M L)$. B. Hoffman phase image of the same field; notice the molecular layer $(M L)$ and the internal granule cell layer $(I G L)$ showing no immunoreactivity. Scale bars, $55 \mu \mathrm{m}$.

B30 antigenic determinant may be correlated with a synaptogenetic period both in the mesencephalic trigeminal nucleus and on Purkinje cells.

\section{The trigeminal system}

B30 stains neurons in the mesencephalic trigeminal nucleus, thus providing a molecular marker for a unique group of cells: MesV neurons constitute the only primary sensory neurons in the CNS. B30 staining allowed us to trace their axons, some of them extending into the cerebellum. The expression of the B30 antigen is transient and seems to be heterogenous from cell to cell, correlating it with the differentiation of the nucleus and of individual neurons. By in vivo staining experiments with postnatal animals and by staining cells in primary cultures, we were able to confirm the association of the antigen with the cell surface and to demonstrate its existence on live cells. Other primary sensory neurons of the PNS, specifically neurons in other cranial nerves and in dorsal root ganglia, also exhibit B30 immunoreactivity on both their peripheral and central projections (data not included). The characteristics and time course of their immunoreactivity seem to follow those of the trigeminal neurons (see Fig. 3).

\section{The cerebellum}

B30 defines different cerebellar layers during development, independently of the trigeminal system. Perinatally it labels a set of postmitotic cells ready to migrate, the premigratory granule cells. Purkinje cells, in a monolayer by P5, start staining around P7, and by P12 all the Purkinje cells, their axons, and their dendritic trees are outlined by B30. This corresponds in time to the maturation of their dendritic trees and the formation of synapses by the climbing fibers and by the parallel fibers onto those dendrites (Altman, 1972).

As some Purkinje cells lose B30 immunoreactivity, a banded pattern of staining of these cells appears around P18 and continues into the adult mouse. The existence of such bands of staining of Purkinje cells in an alternating pattern has led to much speculation that it might be related to the plasticity of certain synapses or to a specific afferent source (see Leclerc et al., 1987). There is extensive evidence, anatomical, biochemical and physiological, for a parasagittal zonation of the mammalian cerebellar cortex and also of cortical afferent and efferent projections (for a physiological review, see Scott, 1963; Bloedel and Courville, 1981). Bands similar to those obtained immuno- 

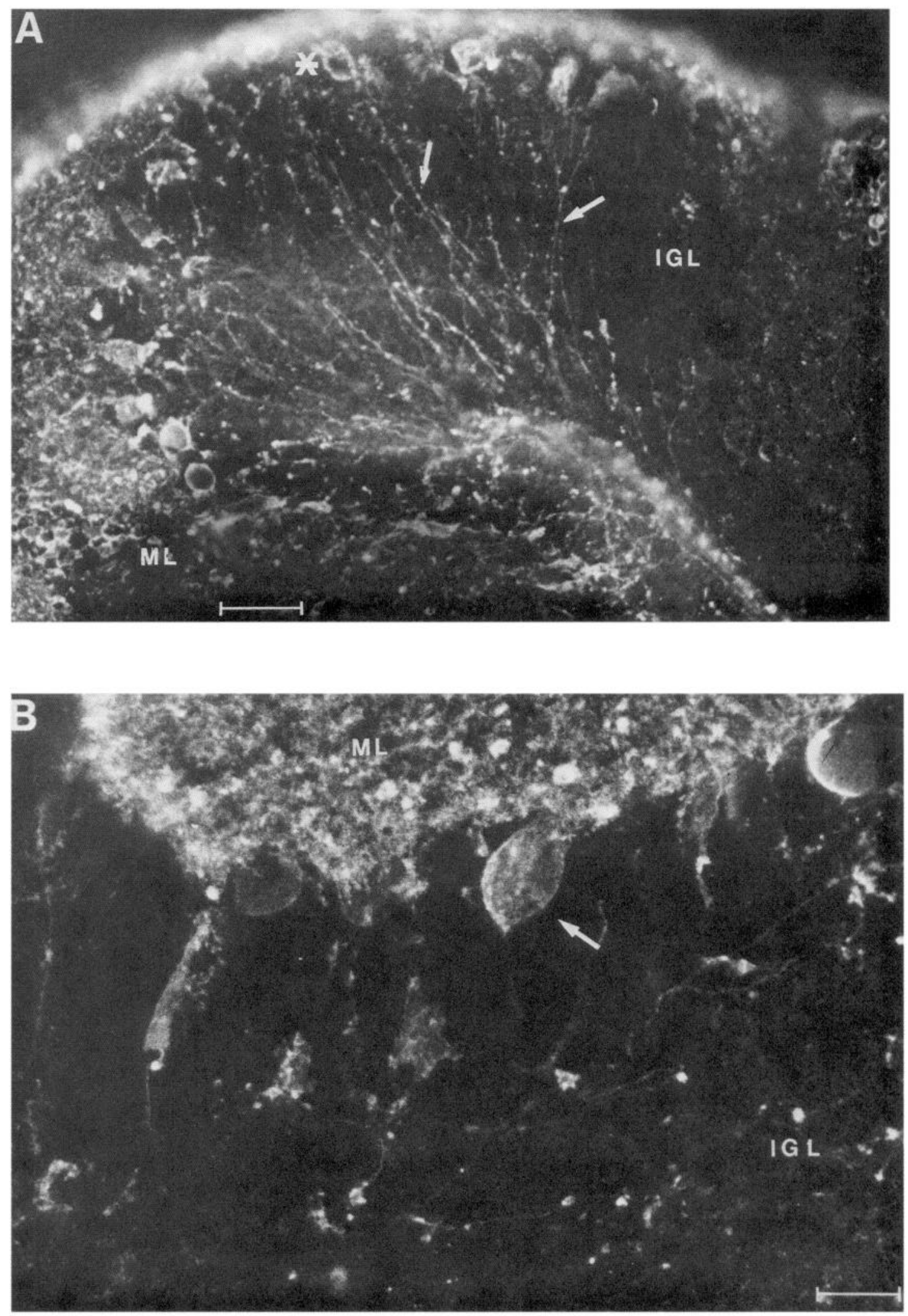

Figure 9. B30 labels all the Purkinje cells, their axons and their dendritic trees by P12. A, Parasagittal section of mouse P12 cerebellum stained with B30. Postmitotic Purkinje cells form a monolayer between the molecular layer $(M L)$ and the internal granule cell layer $(I G L)$ by P5. This monolayer starts staining around P7 and individual Purkinje cells (star) become distinct by P9. Purkinje axons (arrow) go through the IGL to the white matter where they gather to project mainly to the deep cerebellar nuclei. Scale bar, $60 \mu \mathrm{m}$. B, Fluorescent micrograph of B30 stained Purkinje cells and axons. Notice the dense staining of the molecular layer $(M L)$ above the Purkinje cells due to their heavily branched dendritic trees. The IGL is devoid of any immunoreactivity except for the Purkinje axons. Scale bar, $30 \mu \mathrm{m}$. 

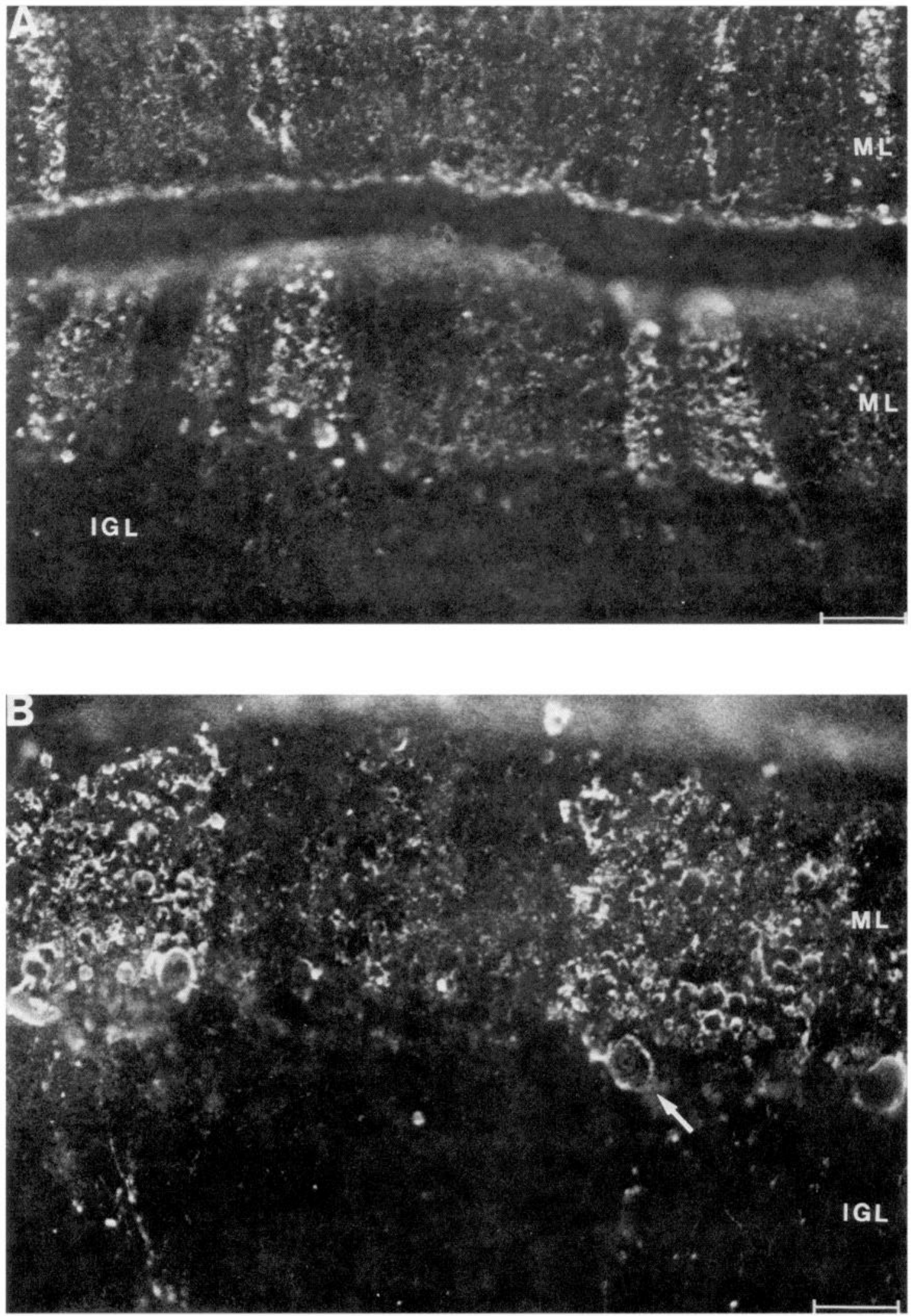

Figure 10. Heterogeneity in B30 immunoreactivity of Purkinje cells at P20. A, Horizontal section of P20 mouse cerebellum stained with B30. Parasagittal bands of B30 immunoreactivity appear alternating with similar bands of cells lacking B30 immunoreactivity. These bands are mostly seen in the vermis. Scale bar, $120 \mu \mathrm{m}$. B. Micrograph of a similar field as in $(A)$. The bands are usually from 5 to 10 cells wide and include the Purkinje cell bodies (arrow), their axons and dendritic trees. Scale bar, $60 \mu \mathrm{m}$. C, Horizontal section of a P18 mouse cerebellum folium from the left hemisphere. Narrow, positively immunoreactive bands of cells, most often only one cell wide are found mostly in the hemispheres of late postnatal mouse cerebellum. Scale bar, $120 \mu \mathrm{m}$. IGL, internal granule cell layer; $M L$, molecular layer. 


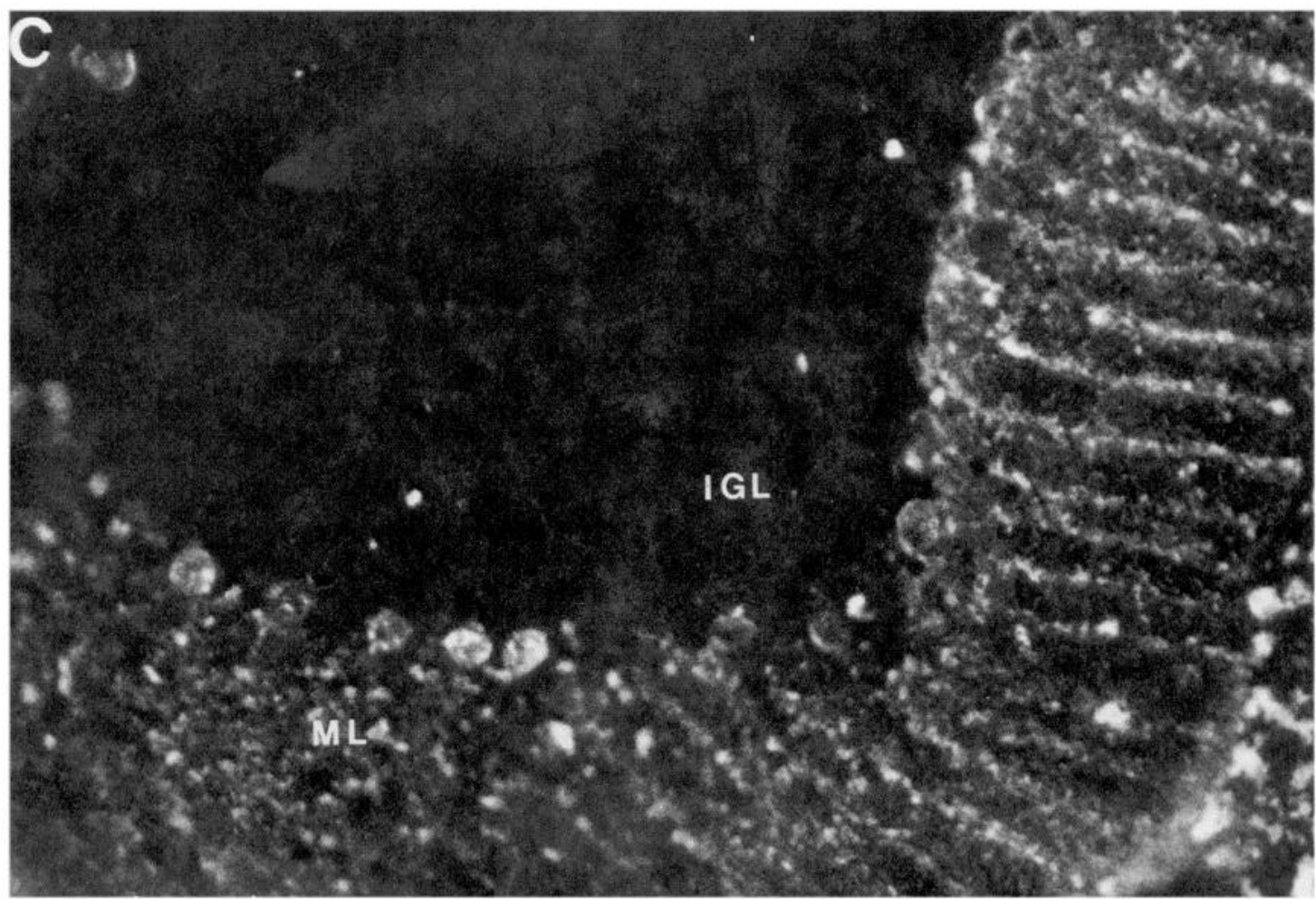

Figure 10. Continued.

histochemically with B30 have been seen in the cerebellar cortex of immature cats stained for acetylcholinesterase (Marani and Voogd, 1977) and have also been observed in the rat cerebellum by Hawkes and Leclerc (1987). The latter used an anti-microtubule associated protein antibody (anti-zebrin) and showed antigen expression spreading throughout the cerebellar cortex during the second postnatal week. Subsequently, immunoreactivity is suppressed in a subset of the Purkinje cells, thus developing the adult pattern of parasagittal antigenic bands. Preliminary experiments have shown that the B30-positive regions correspond to the anti-zebrin-positive areas (R. Hawkes, personal communication).

\section{Technical considerations}

We sought cell surface antigens that would appear on unfixed cells and that would define rare populations of neurons. Our initial approach aimed neither to bias the immune recognition process nor to alter the conformation of the antigens in any way. Using whole-cell suspensions from embryonic brains as immunogen was successful in enriching for cell surface antigens. In the original fusion, $10 \%$ of the wells screened contained a hybridoma line secreting antibodies against antigens located at the cell surface.

Our screening procedures tried to combine both efficiency and accuracy while extending our range of detection. Triturating the brain into very small pieces allowed us to look for rare activities while surveying a representative sample of the developing CNS. Staining fresh chunks of tissue enabled us to distinguish surface staining and to preserve some of the cell-cell relationships during the early screenings. Subsequently, brains of different embryonic and postnatal stages were sliced in order to verify and to localize the specific $\mathrm{mAb}$ binding. Thick fresh sections were used for immunohistochemistry: they preserve the morphological and chemical integrity of the cells and their environment, while still allowing enough penetration to give a good perspective of the neuronal interactions.

\section{Functional considerations of the B30 antigen}

B30 defines 3 homogeneous groups of CNS neurons during varying periods of their maturation: (1) MesV neurons from a time of early axon outgrowth and guidance (E10) through a time of synapse formation, postnatally; (2) premigratory, postmitotic granule cells in the early postnatal cerebellum; and (3) the Purkinje cells during a period of synapse formation and dendritic tree maturation.

In light of recent reports, it has become evident that not only glycoproteins on the cell surface, but also cell surface gangliosides may be involved in cellular interactions and adhesion (Cheresh et al., 1986; Sariola et al., 1988). Specifically, gangliosides are thought to redistribute actively into discrete areas of the cell, and this may cause synergism with cell surface receptors by creating an appropriate electrostatic environment (Cheresh and Klier, 1986; Cheresh et al., 1986; Burns et al., 1988). Moreover, biochemical data show that GD2 augments vitronectin receptor function in the presence of $\mathrm{Ca}^{2+}$ (Cheresh et al., 1987). The B30 epitope is carried on a minor ganglioside. Much like cell surface molecules involved in differential adhesion and axon guidance, surface molecules involved during final target recognition and formation of specific synapses (synaptogenetic molecules) may act in a combinatorial and synergistic fashion. Rare gangliosides could be used as part of a combinatorial recognition system, possibly reflecting different modifications of 


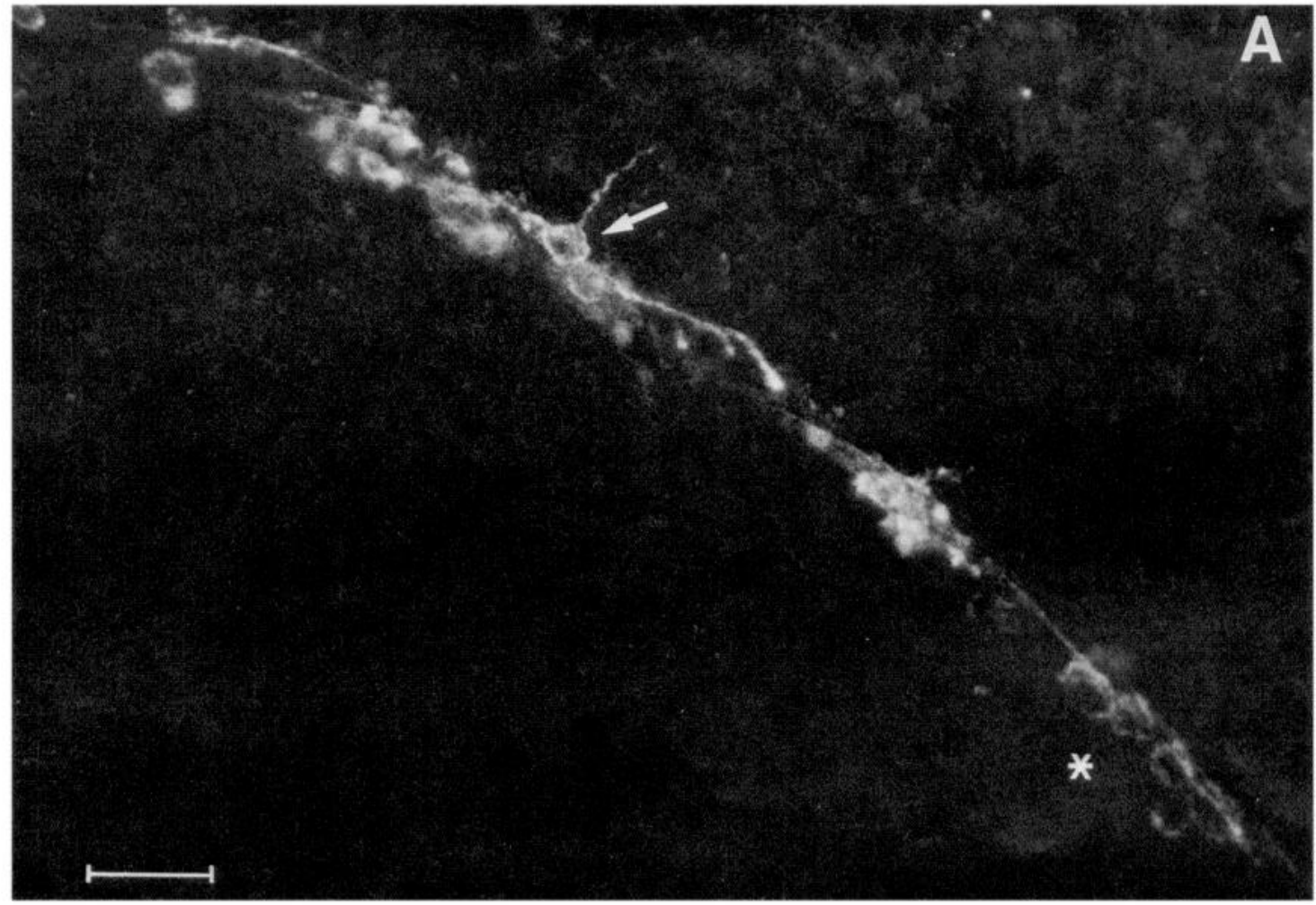

Figure 11. Cell surface association of $\mathrm{B} 30$ antigen. A, Parallel section of a P3 mouse following in vivo staining with B30. B. fluoresceinated secondary antibody were sequentially injected into the brain of a newborn mouse (see text for detail). Subsequently the brain was sliced into $120 \mu \mathrm{m}$ parallel sections for examination. Notice a caudally situated group of MesV cells (star), and, more rostrally, a MesV neuron sending an axon laterally (arrow). Scale bar, $60 \mu \mathrm{m}$. B, B30 staining of live cultures. Embryonic day 13 (E13) mouse trigeminal ganglia were dissociated and single cells were put in culture. Fresh cultures were stained 6 days after plating. Scale bar, $60 \mu \mathrm{m}$. $C$, Hoffman phase micrograph of the same field. The arrow points to the B30 immunoreactive neuron. Scale bar, $60 \mu \mathrm{m}$.

Figure 12. B30 immunostaining of a TLC plate of acidic glycolipids. Acidic glycolipids containing $0.5-1 \mu \mathrm{g}$ sialic acid were applied to the plate and developed with chloroform/methanol/ $0.25 \%$ aqueous $\mathrm{CaCl}_{2}(60: 40: 10)$. (a) Acidic glycolipids from P12 mouse cerebellum; (b) acidic glycolipids from P7 mouse midbrain and brain stems (dissected to include the B30 immunoreactive areas); (c) acidic glycolipids from P7 mouse cortex. Ganglioside standards from Calbiochem $\left(\mathrm{GM}_{1}, \mathrm{GD}_{1 \mathrm{a}}\right.$, $\mathrm{GD}_{1 \mathrm{~b}}, \mathrm{GT}_{1 \mathrm{~b}}$ ) were run in parallel and stained with resorcinol; $\mathrm{GD}_{3}$ doublet migration was determined by R24 binding (data not shown).

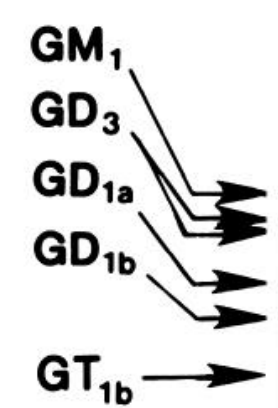

(a) 

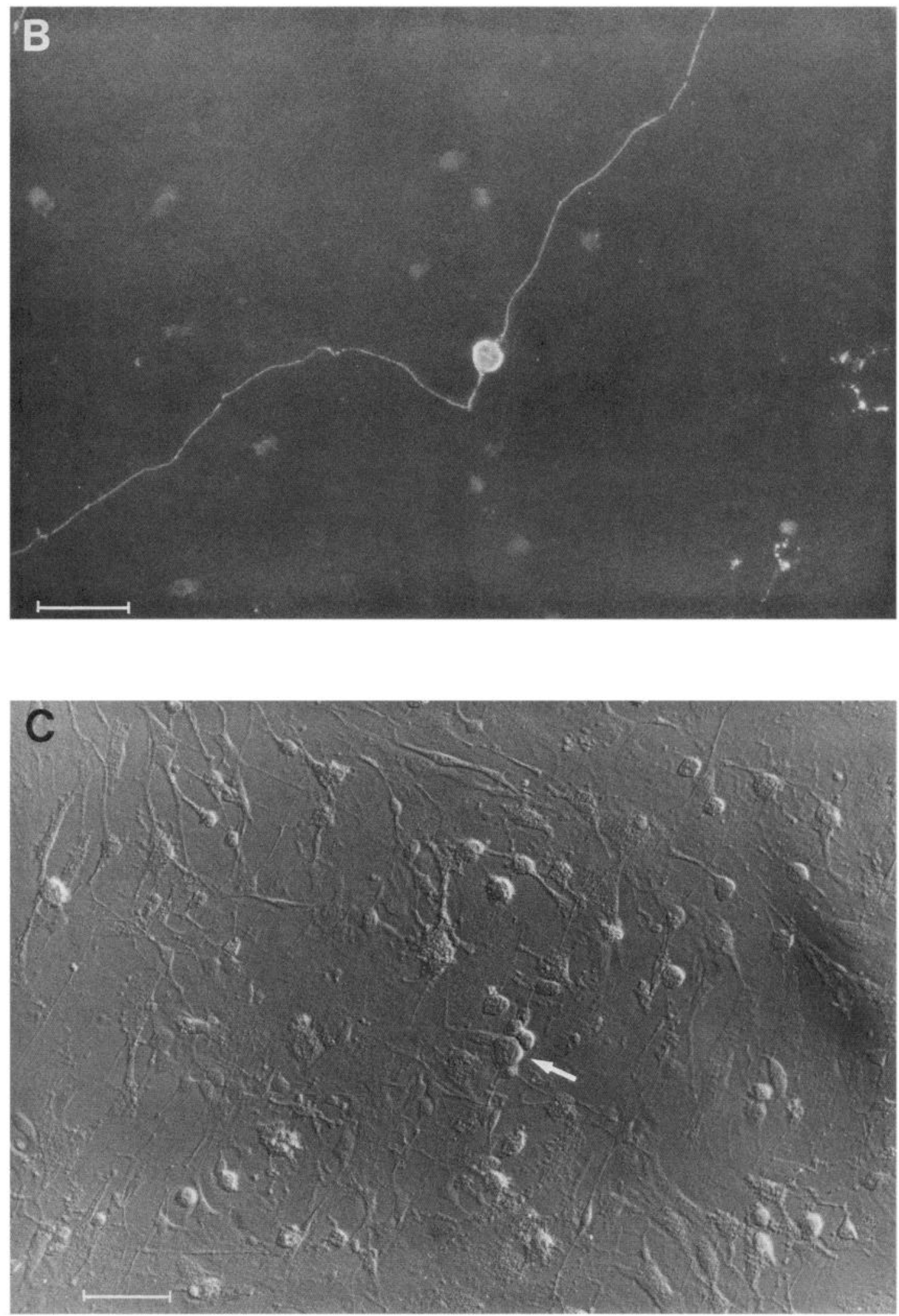

Figure 11. Continued. 
an underlying molecule. Thus, the B30 antigen might be part of such guiding and synaptogenetic arrays, used differently in different systems.

\section{References}

Alley, K. E. (1973) Quantitative analysis of the synaptogenetic period in the trigeminal mesencephalic nucleus. Anat. Rec. 177: 49-60.

Alley, K. E. (1974) Morphogenesis of the trigeminal mesencephalic nucleus in the hamster: Cytogenesis and neurone death. J. Embryol. Exp. Morphol. 31: 99-121.

Altman, J. (1972) Postnatal development of the cerebellar cortex in the rat. II. Phases in the maturation of Purkinje cells and of the molecular layer. J. Comp. Neurol. 145: 399-464.

Baechtel, S., and M. D. Prager (1982) Interaction of antigens with dimethyldioctadecylammonium bromide, a chemically defined biological response modifier. Cancer Res. 42: 4959-4963.

Baker, R., and R. Llinás (1971) Electrotonic coupling between neurons in the rat mesencephalic nucleus. J. Physiol. (Lond.) 212: 45-63.

Barnstable, C. J. (1980) Monoclonal antibodies which recognize different cell types in the rat retina. Nature 286: 231-235.

Bastiani, M. J., A. L. Harrelson, P. M. Snow, and C. S. Goodman (1987) Expression of fasciclin I and II glycoproteins on subsets of axon pathways during neuronal development in the grasshopper. Cell 48: 745755 .

Bloedel, J. M., and J. Courville (1981) Cerebellar afferent systems. In Handbook of Physiology, V. Brookes, ed., pp. 735-829, Williams \& Wilkins, Baltimore

Burns, G. F., C. M. Lucas, G. W. Krissansen, J. A. Werkmeister, D. B. Scanlon, R. J. Simpson, and M. A. Vadas (1988) Synergism between membrane gangliosides and Arg-Gly-Asp-directed glycoprotein receptors in attachment to matrix proteins by melanoma cells. J. Cell Biol. 107: 1225-1230.

Cheresh, D. A., and F. G. Klier (1986) Disialoganglioside GD2 distributes into substrate-associated microprocesses on human melanoma cells during their attachment to fibronectin. J. Cell Biol. 102: 1887-1897.

Cheresh, D. A., M. D. Pierschbacher, M. A. Herzig, and K. Mujoo (1986) Disialogangliosides GD2 and GD3 are involved in the attachment of human melanoma and neuroblastoma cells to extracellular matrix proteins. J. Cell Biol. 102: 688-696.

Chcresh, D. A., R. Pytcla, M. D. Pierschbacher, F. G. Klier, E. Ruoslahti, and R. A. Reisfield (1987) An Arg-Gly-Asp-directed receptor on the surface of human melanoma cells exists in a divalent cationdependent functional complex with the disialoganglioside GD2. J. Cell Biol. 105: 1163-1173.

Cohen, J., and S. Y. Selvendran (1981) A neuronal cell surface marker is found in the CNS but not in peripheral neurons. Nature 291:421423.

Constantine-Paton, M., A. Blum, R. Mendez-Otero, and C. Barnstable (1986) A cell surface molecule distributed in a dorsoventral gradient in the perinatal rat retina. Nature 324: 459-462.

Fujita, S. C., and K. Obata (1984) Monoclonal antibodies demonstrate regional specificity in the spinal funiculi of the chick embryo. Neurosci. Res. 1: 131-148.

Galfre, G., S. C. Howe, C. Milstein, G. W. Butcher, and J. C. Howard (1977) Antibodies to major histocompatibility antigens produced by hybrid cell lines. Nature 266: 550-552.

Goodman, C. S., M. J. Bastiani, C. Q. Doe, S. duLac, S. L. Helfand, J. Y. Kuwada, and J. B. Thomas (1984) Cell recognition during neuronal development. Science 225: 1271-1279.

Hawkes, R., and N. Leclerc (1987) Antigenic map of the rat cerebellar cortex: The distribution of parasagittal bands as revealed by monoclonal anti-Purkinje cell antibody mabQ113. J. Comp. Neurol. 256: $29-41$.

Hinrichsen, C. F. L. (1970) Coupling between cells of the mesencephalic trigeminal nucleus. J. Dent. Res. 49: 1369-1373.

Hinrichsen, C. F. L., and L. M. H. Larramendi (1968) Synapses and cluster formation of the mouse mesencephalic fifth nucleus. Brain Res. 7: 296-299.

Hinrichsen, C. F. L., and L. M. H. Larramendi (1969) Features of trigeminal mesencephalic nucleus structure and organization. Am. J. Anat. 126: 497-506.
Hiscock, J., and C. Straznicky (1986) The formation of axonal projections of the mesencephalic trigeminal neurones in chick embryos. J. Embryol. Exp. Morphol. 93: 281-290.

Hood, L., H. V. Huang, and W. J. Dryer (1977) The area-code hypothesis: The immune system provides clues to understanding the genetic and molecular basis of cell recognition during development. J. Supramol. Struct. 7: 531-559.

Jessel, T. M. (1988) Adhesion molecules and the hierarchy of neural development. Rev. Neuron 1: 3-13.

Larramendi, L. M. H. (1969) Analysis of synaptogenesis in the cerebellum of the mouse. In Neurobiology of Cerebellar Evolution and Development, R. Llinás, ed., pp. 803-843, Am. Med. Assoc. Ed. \& Res. Foundation, Chicago.

Leclerc, N., C. Gravel, and R. Hawkes (1987) Parasagittal zonation in the cerebellar cortex develops independent of afferent input. Soc Neurosci. Abstr. 308: 17.

Marani, E., and J. Voogd (1977) An acetylcholinesterase band pattern in the molecular layer of the cat cerebellum. J. Anat. 124: 335-345.

Mason, C. A. (1985) Growing tips of embryonic cerebellar axons in vivo. J. Neurosci. Res. 13: 55-73.

McKay, R., and S. V. Hockfield (1982) Monoclonal antibodies distinguish antigenically discrete neuronal types in the vertebrate central nervous system. Proc. Natl. Acad. Sci. USA 79: 6747-6751.

McKay, R. D. G., S. V. Hockfield, J. Johansen, I. Thompson, and K. Frederickson (1984) Surface molecules identify groups of growing axons. Science 222: 678-684.

Mendez-Otero, R., B. Schlosshauer, C. Barnstable, and M. ConstantinePaton (1988) A developmentally regulated antigen associated with neural cell and process migration. J. Neurosci. 8: 564-579.

Meynert, T. H. (1872) The brain of mammals. In Stricker's Manual of Histology (English trans.), pp. 650-766, William Wood, New York.

Mori, K., S. C. Fujita, Y. Watanabe, K. Obata, and O. Hayaishi (1987) Telencephalon-specific antigen identified by monoclonal antibody. Proc. Natl. Acad. Sci. USA 84: 3921-3925.

Moskal, J. R., and A. E. Schaffner (1986) Monoclonal antibodies to the dentate gyrus: Immunocytochemical characterization and flow cytometric analysis of hippocampal neurons bearing a unique cellsurface antigen. I. Neurosci. 6: 2045-2053.

Narayanan, C. H., and Y. Narayanan (1978) Determination of the embryonic origin of the mesencephalic nucleus of the trigeminal nerve in birds. J. Embryol. Exp. Morphol. 43: 85-105.

Rayburn, H., H. M. Wu, D. Stainier, E. Bennett, and W. Gilbert (1987) Monoclonal antibodies directed at the surfaces of embryonic brain cells. Soc. Neurosci. Abstr. 391: 3.

Roseman, S. (1974) The biosynthesis of cell-surface components and their potential role in intercellular communication. In The Neurosciences, Third Study Program, F. O. Schmitt and F. G. Worden, eds., pp. 795-804, MIT Press, Cambridge, MA.

Saigal, R. P., A. N. Karamanlidis, J. Voogd, O. Mangana, and H. Michaloudi (1980) Secondary trigeminocerebellar projections in sheep studied with the horseradish peroxidase tracing method. J. Comp. Neurol. 189: 537-553.

Sariola, H., E. Aufderheide, H. Bernhard, S. Henke-Fahle, W. Dippold, and P. Ekblom (1988) Antibodies to cell surface ganglioside GD3 perturb inductive epithelial-mesenchymal interactions. Cell $54: 235-$ 245.

Schlosshauer, B., A. S. Blum, R. Mendez-Otero, C. J. Barnstable, and M. Constantine-Paton (1988) Developmental regulation of ganglioside antigens recognized by the JONES antibody. J. Neurosci. 8: 580592.

Schwarting, G. A., F. B. Jungalwala, D. K. Chou, A. M. Boyer, and M. Yamamoto (1987) Sulfated glucuronic acid-containing glycoconjugates are temporally and spatially regulated antigens in the developing mammalian nervous system. Dev. Biol. 120:65-76.

Scott, T. G. (1963) A unique pattern of localization in the cerebellum. Nature 200:793.

Somana, R., N. Kotchabhakdi, and F. Walberg (1980) Cerebellar afferents from the trigeminal sensory nuclei in the cat. Exp. Brain Res. 38: 57-64.

Sperry, R. W. (1963) Chemoaffinity in the orderly growth of nerve fiber patterns and connections. Proc. Natl. Acad. Sci. USA 50: 703710 .

Stainier, D., H. M. Wu, H. Rayburn, E. Bennett, and W. Gilbert (1987) Monoclonal cell surface antibody defining mesencephalic trigeminal nucleus. Soc. Neurosci. Abstr. 391: 3. 
Stallcup, W. B., L. L. Beasley, and J. M. Levine (1985) Antibody against nerve growth factor-inducible large external (NILE) glycoprotein labels nerve fiber tracts in the developing rat nervous system. J. Neurosci. 5: 1090-1101.

Steller, H., K. F. Fishbach, and G. M. Rubin (1987) Disconnected: A locus required for neuronal pathway formation in the visual system of Drosophila. Cell 50: 1139-1153.

Suzuki, K. (1965) The pattern of mammalian brain ganglionides. III. Regional and developmental differences. J. Neurochem. 12: 969-979.
Weiss, P. (1947) The problem of specificity in growth and development. Yale J. Biol. Med. 19: 235-278.

Yamamoto, M., A. M. Boyer, J. E. Crandall, M. Edwards, and H. Tanaka (1986) Distribution of stage specific neurite-associated proteins in the developing murine nervous system recognized by a monoclonal antibody. J. Neurosci. 6: 3576-3594.

7ipser, B. and R. McKay (1981) Monoclonal antibodies distinguish identifiable neurones in the leech. Nature 289: 549-554. 